\title{
BIOLOGI DAN TRANSFORMASI BELALANG KEMBARA LOCUSTA MIGRATORIA MANILENSIS MEYEN (ORTHOPTERA: ACRIDIDAE) PADA BEBERAPA TINGKAT KEPADATAN POPULASI DI LABORATORIUM
}

\author{
Hamim Sudarsono ${ }^{1}$, Rosma Hasibuan ${ }^{1}$, dan Damayanti Buchori ${ }^{2}$
}

\begin{abstract}
Biology and Transformation of the Migratory Locust Locusta migratoria manilensis Meyen (Orthoptera: Acrididae) at Several Laboratory Population Density Levels. The migratory locust, Locusta migratoria manilensis Meyen (Orthoptera: Acrididae) is one of insect pests in Indonesia that undergoes a unique polymorphic biology. The locust develops a transformation phase which is triggered mainly by high population density. Its recent outbreaks in several regions of Indonesia cause major concern and control strategies must be developed to strengthen control efforts in the future. Its unique polymorphic phenomenon, therefore, must be investigated thoroughly for the basis of management of the outbreak. Due to its agility and its long range flying ability, the most realistic technique to study behavioral and morphological change of the locust is in controlled condition at a laboratory or a green house facility. The experiment was aimed to study effects of colony densities on the biology and transformation process of the migratory locust. More specifically, the experiment was to study effects of population density on the feeding activity, mortality rate, and the ratio of $\mathrm{F} / \mathrm{C}$ and $\mathrm{E} / \mathrm{F}$ of the migratory locust $L$. migratoria manilensis. The population densities were simulated in colonies at 2, 5, 10, 20, dan 30 couples per cage (cage size: $45 \times 45 \times 90 \mathrm{~cm}$ ) reared in a green house. Results of the experiment show that, in general, higher densities of the migratory locust colonies tended to feed more rigorously than those of the less dense colonies. The locust remained in solitary phase at the density of 2-5 couples per cage whereas the transient phase occured at the density of 10-20 couples per cage. The colonies transformed to gregarious stage when their densities were 30 couples per cage or higher. Mortality percentage tended to be higher at colonies with higher density, especially for the third instar of the migratory locust.
\end{abstract}

Key words: gregarious, Locusta migratoria manilensis Meyen, population density, solitar, transformation, transient

\section{PENDAHULUAN}

Serangan hama belalang kembara Locusta migratoria manilensis Meyen (Orthoptera: Acrididae) merupakan fenomena yang mengejutkan banyak kalangan selama beberapa tahun terakhir di Indonesia, terutama sejak terjadinya eksplosi populasi hama ini pada tahun 1998. Areal pertanian di beberapa wilayah di Indonesia mengalami serangan hama belalang kembara dengan tingkat kerusakan yang cukup parah. Provinsi Lampung dan Sumatera Bagian Selatan termasuk wilayah yang paling parah mengalami eksplosi populasi hama belalang ini. Selama bulan
April hingga Mei 1998, ribuan hektar areal pertanian yang dilewati gerombolan belalang mengalami kerusakan total. Ribuan hektar tanaman padi menjelang panen dan tanaman jagung yang sedang berbunga hancur dalam waktu satu malam oleh hama yang sangat rakus ini (Kompas, 4 Mei 1998). Sejak ledakan populasi yang pertama tersebut, selanjutnya populasi besar belalang kembara sering terjadi di Sumbagsel dan di daerah-daerah lain seperti Nusa Tenggara Timur, dan Kalimantan Barat. Diduga di daerah-daerah tersebut telah terdapat sentra-sentra populasi belalang kembara yang setiap saat bisa menjadi wabah apabila faktor alam mendukung.

\footnotetext{
${ }^{1}$ Dosen Jurusan Proteksi Tanaman, Fakultas Pertanian, Universitas Lampung; penulis untuk korespondensi.

${ }^{2}$ Dosen Departemen Proteksi Tanaman, Fakultas Pertanian, Institut Pertanian Bogor
} 
Fenomena wabah belalang kembara sangat erat kaitannya dengan biologi dan perilaku yang sangat khas dari hama ini. Sebagai salah satu jenis belalang kembara, L.m.manilensis merupakan spesies polimorfik yang secara morfologi terdapat perbedaanperbedaan yang jelas antara satu fase dengan lainnya. Belalang kembara diketahui mengalami tiga transformasi populasi yang antara lain dipicu oleh tingkat kepadatannya (Loher, 1990), yaitu fase soliter (populasi rendah dan berperilaku individual), fase transisi (mulai berkelompok), dan fase gregarius (kelompok-kelompok belalang bergabung dan membentuk swarm yang menjadi sangat rakus dan merusak) (Ellis, 1953; Kalshoven, 1981). Dengan demikian, belalang kembara dapat berubah dari fase soliter menjadi fase gregarius jika kenaikan kepadatan populasi menyebabkan populasi belalang kembara fase soliter saling berdekatan dan beragregasi. Agregasi ini selanjutnya menyebabkan berfungsinya feromon khusus yang memicu terjadinya proses gregarisasi (Loher, 1990).

Selain perubahan perilaku, terdapat juga perubahan morfometrik belalang kembara yang baru terlihat beberapa waktu kemudian. Perubahanperubahan ini antara lain bentuk dan morfologi tubuh, jumlah ovariol, berat tubuh, ukuran nimfa, jumlah fase nimfa, lama hidup, dan beberapa karakteristik biologis lainnya. Perubahan morfologi bagian-bagian tubuh belalang kembara yang telah diketahui dan digunakan sebagai indikator fase transformasinya antara lain: ukuran panjang femur tungkai belakang (F, femur), panjang sayap depan (E, elitra; istilah yang lebih tepat untuk sayap depan belalang seharusnya tegmina), dan lebar kepala (C, Caput) (LuongSkovmand, 1999; Loher, 1990; Dale \& Tobe, 1990). Dari ukuran-ukuran bagian tubuh tersebut maka selanjutnya dapat ditentukan besaran rasio $\mathrm{F} / \mathrm{C}$ dan $\mathrm{E} / \mathrm{F}$ sebagai indikator fase transformasi yang sedang dialami oleh belalang kembara pada suatu wilayah.

Sehubungan dengan perubahan morfometrik dan perilaku tersebut maka keberhasilan program pengendalian belalang kembara memerlukan sistem pemantauan populasi yang mampu menduga kapan populasi belalang akan mengalami fase gregarius. Tindakan pengendalian hanya akan efektif apabila dilakukan ketika populasi meningkat tetapi sebelum terbentuknya fase gregarius. Oleh karena itu harus dikembangkan sistem pendugaan populasi yang baik untuk mengetahui kapan fase gregarius akan terbentuk pada suatu hamparan atau wilayah. Upaya ini dapat dimulai dengan mempelajari perubahan biologi dan morfologi belalang kembara pada kondisi kepadatan populasi yang berbeda-beda. Mengingat belalang kembara merupakan serangga yang sangat aktif bergerak dengan jangkauan terbang yang sangat jauh, maka cara yang paling realistis untuk mempelajari perubahan perilaku dan morfologi belalang ini adalah dalam kondisi terkontrol di laboratorium atau rumah kaca. Penelitian ini bertujuan menyelidiki pengaruh kepadatan populasi terhadap proses transformasi belalang kembara dilakukan dengan menggunakan belalang fase nimfa. Secara lebih khusus, percobaan ini mempelajari pengaruh kepadatan koloni terhadap daya makan, rasio $\mathrm{F} / \mathrm{C}$ dan $\mathrm{E} / \mathrm{F}$, serta mortalitas belalang kembara.

\section{BAHAN DAN METODE}

Penelitian ini dilaksanakan pada bulan Maret hingga Juni 2000 di Laboratorium Hama Tanaman dan Rumah Kaca Jurusan Proteksi Tanaman, Fakultas Pertanian Universitas Lampung.

Percobaan diawali dengan mengumpulkan belalang kembara soliter dari beberapa lokasi di Lampung. Agar diperoleh populasi awal yang seragam, belalang kembara yang dikumpulkan adalah yang berada dalam fase nimfa instar kedua. Setelah belalang terkumpul, diseleksi individu-individu yang seragam dan sehat yang ditandai dengan gerakangerakannya yang lincah. Belalang kembara yang terpilih ini kemudian dipelihara dalam kurungan berukuran 45 x 45 x $90 \mathrm{~cm}$ yang terbuat dari kerangka kayu dan kasa anti nyamuk. Pada bagian bawah kurungan diberi lapisan tanah setebal kurang lebih setebal $10 \mathrm{~cm}$. Untuk menjaga kelembaban tanah, tanah disiram secara periodik dengan air dalam jumlah cukup tetapi tidak terlalu lembab atau terlalu basah.

Untuk menyimulasi kondisi kepadatan populasi yang berbeda-beda, belalang dikurung dalam kepadatan 2, 5, 10, 20, dan 30 pasang per kurungan. Setiap kepadatan diulang 5 kali. Setiap koloni secara rutin diberi pakan berupa rumput Setaria dan daun jagung. Untuk mengetahui berat pakan yang dimakan oleh belalang kembara, pakan ditimbang sebelum diberikan ke dalam kurungan dan 24 jam kemudian ditimbang berat pakan yang tersisa. Untuk mengetahui penyusutan berat pakan yang disebabkan oleh penguapan (bukan karena dimakan belalang kembara), ditimbang satu set pakan kontrol yang dimasukkan ke dalam kurungan tetapi tidak berisi belalang kembara. Data berat pakan yang diolah selanjutnya adalah 
perbedaan berat pakan selama 24 jam akibat konsumsi oleh belalang kembara yang telah dikoreksi dengan rerata berat penyusutan karena penguapan.

Dari masing-masing tingkat kepadatan ini selanjutnya diamati: (1) daya makan belalang yang diukur dari jumlah pakan yang dikonsumsi oleh serangga uji; (2) ukuran morfologi penciri penting status fase belalang kembara, yaitu panjang femur tungkai belakang (F, femur), sayap depan (E, elitra), dan lebar kepala (C, caput); serta (3) persentase mortalitas belalang kembara pada masing-masing kepadatan. Mengingat adanya perbedaan aktivitas makan selama perkembangan nimfa belalang kembara dari instar 2 hingga dewasa, daya makan belalang dikelompokkan ke dalam tiga periode, yaitu periode 1 - 15 hari (instar 2 - 3), periode hari $16-30$ (instar 4 -5), dan periode hari 31 - 45 (fase dewasa). Sedangkan morfologi yang merupakan penciri penting fase belalang kembara (femur, sayap, dan caput) diukur pada belalang fase dewasa. Hasil pengamatan daya makan (berat pakan yang dikonsumsi belalang per hari), ukuran bagian tubuh (femur, sayap, dan caput), serta mortalitas koloni dianalisis dengan sidik ragam dan dilanjutkan dengan pembandingan nilai tengah dengan Uji BNT. Pengolahan data dilakukan dengan menggunakan software SAS versi 8.01 (SAS Institute, 2000). Data ukuran femur (F), sayap (E), dan caput (C) digunakan untuk menghitung rasio $\mathrm{E} / \mathrm{F}$ dan $\mathrm{F} / \mathrm{C}$. Nilai rasio $\mathrm{E} / \mathrm{F}$ dan $\mathrm{F} / \mathrm{C}$ ini selanjutnya digunakan untuk menentukan fase belalang kembara dengan menggunakan koefisien kriteria LuongSkovmand (1999) (Tabel 1).

\section{HASIL DAN PEMBAHASAN}

Belalang kembara yang dipelihara di rumah kaca dalam kepadatan populasi tinggi secara umum cenderung lebih rakus daripada mereka yang dipelihara dalam kepadatan populasi rendah. Pada kepadatan 2 - 5 pasang per kurungan, daya makan belalang kembara cenderung tetap atau bahkan menurun selama 45 hari pengamatan. Pada tingkat kepadatan ini, daya makan belalang kembara adalah 0,56 - 2,06 g/ekor/hari. Kecenderungan ini juga terlihat pada koloni dengan kepadatan 10 pasang belalang kembara per kurungan walaupun aktivitas makannya relatif lebih tinggi. Kisaran volume makan belalang kembara pada tingkat kepadatan 10 pasang per kurungan adalah 2,33 - 2,73 g/ekor/hari. Yang menarik dari tingkat kepadatan 2 - 10 pasang ini adalah bahwa pada pertengahan pertumbuhan (pengamatan hari ke 16 - 30), intensitas makan belalang kembara relatif rendah dibandingkan dengan pada awal atau akhir perkembangan belalang kembara. Sementara itu, pada koloni 20 - 30 pasang per kurungan, aktivitas makan belalang kembara cenderung bertambah ketika umurnya bertambah. Pada kondisi koloni paling padat ini belalang kembara menjadi lebih rakus dan volume makanan secara signifikans lebih tinggi daripada koloni belalang kembara dengan kepadatan yang lebih rendah. Aktivitas makan belalang kembara pada kondisi kepadatan 20 - 30 pasang adalah 3,39 - 4,72 g/ekor/hari (Tabel 2).

Tabel 1. Ciri morfologis tiga fase transformasi dari populasi belalang kembara Afrika (Locusta migratoria migratoriodes) (Luong-Skovmand, 1999)

\begin{tabular}{ccccc}
\hline $\begin{array}{c}\text { Rasio Bagian } \\
\text { Tubuh }\end{array}$ & Jenis Kelamin & Fase Transformasi & \\
& & Soliter & Transien & Gregarius \\
\hline E/F & Jantan & $1,40-1,79$ & $1,79-2,09$ & $2,09-$ \\
& Betina & $1,40-1,81$ & $1,81-2,18$ & $2,18-$ \\
\hline F/C & Jantan & $3,67-4,00$ & $2,95-3,67$ & $--2,95$ \\
& Betina & $3,46-4,00$ & $2,85-3,46$ & $-2,85$ \\
\hline
\end{tabular}

Keterangan: $\mathrm{E}$ = panjang sayap depan; $\mathrm{F}$ = panjang femur tungkai belakang ;

$\mathrm{C}=$ lebar maksimum kepala 
Tabel 2. Daya makan belalang kembara yang dihitung pada beberapa tingkat kepadatan populasi.

\begin{tabular}{cccc}
\hline $\begin{array}{c}\text { Perlakuan (Jumlah } \\
\text { Belalang/Kurungan) }\end{array}$ & \multicolumn{3}{c}{ Rerata Daya Makan Belalang Kembara (g/ekor/hari) } \\
& Hari 1-15 & Hari 16-30 & Hari 31-45 \\
\hline 2 pasang & $1,13 \pm 0,01 \mathrm{~d}$ & $1,02 \pm 0,02 \mathrm{~d}$ & $0,56 \pm 0,02 \mathrm{e}$ \\
5 pasang & $1,69 \pm 0,01 \mathrm{c}$ & $2,06 \pm 0,03 \mathrm{c}$ & $1,48 \pm 0,03 \mathrm{~d}$ \\
10 pasang & $2,39 \pm 0,01 \mathrm{~b}$ & $2,73 \pm 0,02 \mathrm{~b}$ & $2,33 \pm 0,02 \mathrm{c}$ \\
20 pasang & $3,39 \pm 0,01 \mathrm{a}$ & $3,74 \pm 0,02 \mathrm{a}$ & $3,95 \pm 0,01 \mathrm{~b}$ \\
30 pasang & $3,39 \pm 0,00 \mathrm{a}$ & $4,02 \pm 0,11 \mathrm{a}$ & $4,72 \pm 0,21 \mathrm{a}$ \\
\hline Nilai-F & 760,57 & 160,85 & 82,34 \\
\hline Nilai-P & 0,0001 & 0,0001 & 0,0001 \\
\hline
\end{tabular}

Keterangan: Nilai-F dan Nilai-P diperoleh dari analisis ragam dan Uji BNT pada taraf nyata 5\%. Nilai ratarata sekolom yang diikuti huruf yang sama tidak berbeda nyata menurut uji BNT pada taraf nyata $5 \%$.

Selain berpengaruh terhadap aktivitas makan, tingkat kepadatan koloni belalang kembara juga berpengaruh terhadap morfologinya, khususnya dalam hal ini terhadap ukuran panjang femur tungkai belakang, panjang sayap, dan lebar maksimum kepala atau caput. Hasil pengukuran terhadap ketiga bagian organ tersebut memperlihatkan bahwa secara umum belalang kembara dewasa dalam koloni berkepadatan tinggi cenderung mempunyai ukuran femur yang lebih pendek, sayap lebih panjang, serta caput lebih lebar. Hal ini terjadi baik pada belalang kembara jantan maupun betina (Tabel 3). Berdasarkan ukuran-ukuran morfologi di atas, rasio E/F dan F/C yang diperoleh (Tabel 4) memperlihatkan bahwa berdasarkan kriteria Luong-Skovmand (1999) (Tabel 1) baik belalang kembara jantan maupun betina tetap berada dalam fase soliter pada kepadatan koloni 2-5 pasang per kurungan. Selanjutnya belalang kembara berubah dari fase soliter ke fase transien pada kepadatan koloni 1020 pasang per kurungan. Perubahan ke fase gregarius terjadi ketika koloni belalang kembara berada pada kepadatan 30 pasang per kurungan.

Mengingat hasil-hasil di atas diperoleh pada kondisi kurungan dengan luas volume \pm 45 x 45 x 90 $\mathrm{cm}$, dari percobaan ini belum bisa untuk disimpulkan pada kepadatan populasi berapa dalam kondisi lapangan terbuka mulai terjadi proses gregarisasi yang sesungguhnya. Namun demikian, percobaan ini setidaknya membuktikan bahwa kepadatan populasi belalang kembara merupakan pemicu utama terjadinya proses transformasi serangga tersebut sebagaimana dilaporkan oleh Loher (1990). Percobaan ini sekaligus juga memperkuat laporan
Kalshoven (1981) dan Ellis (1953) yang menyatakan bahwa dalam kepadatan yang tinggi belalang kembara menjadi lebih merusak karena lebih rakus. Aktivitas makan yang semakin meningkat pada koloni yang semakin padat kemungkinan ada hubungannya dengan proses gregarisasi yang terjadi pada belalang kembara ketika kepadatan populasinya meningkat. Proses ini diduga diinisiasi oleh senyawa kimia sejenis feromon yang diproduksi oleh kelenjar di dalam individuindividu belalang kembara dan feromon ini berpengaruh terhadap individu lain yang melakukan kontak atau berada di sekitarnya (Karlson \& Butenandt, 1959). Feromon yang diproduksi dalam proses gregarisasi ini memicu terjadinya perubahan fisiologis dan selanjutnya dapat diikuti oleh perubahan morfometrik, perilaku, dan genetik. Sebagian peneliti secara spesifik menyebut feromon ini sebagai feromon gregarisasi (gregarizing pheromone) yang pada fase nimfa dapat memicu terjadinya transisi dari fase soliter ke fase gregarius pada belalang kembara (Nolte, 1976, 1977; Gillet, 1975, 1983).

Proses transformasi belalang kembara dari fase soliter menjadi fase gregarius dipengaruhi oleh beberapa faktor. Faktor utama pemicu proses trnasformasi ini adalah kepadatan populasi. Belalang kembara di Afrika L. m. migratoriode, misalnya, diketahui berubah dari fase soliter menjadi gregarius apabila populasinya mencapai sekitar 2000 ekor per ha. Sementara itu, belalang kembara spesies Schistocera gregaria mengalami transformasi populasi pada tingkat kepadatan 500 individu per ha (Luong-Skovmand, 1999). Proses tranformasi ini 
Tabel 3. Rata-rata panjang femur tungkai belakang, panjang sayap depan, lebar kepala, belalang kembara jantan dan betina setelah dipelihara dalam beberapa tingkat kepadatan.

\begin{tabular}{|c|c|c|c|}
\hline \multirow{2}{*}{$\begin{array}{c}\text { Perlakuan } \\
\text { (Jumlah } \\
\text { belalang/ } \\
\text { kurungan) }\end{array}$} & \multicolumn{3}{|c|}{ Rata-rata Panjang Morfologi Belalang Kembara Jantan } \\
\hline & $\begin{array}{l}\text { Panjang Femur (F) } \\
(\mathrm{cm})\end{array}$ & $\begin{array}{l}\text { Panjang Sayap (Elitra, E) } \\
(\mathrm{cm})\end{array}$ & $\begin{array}{l}\text { Lebar Caput (C) } \\
(\mathrm{mm})\end{array}$ \\
\hline \multicolumn{4}{|c|}{ Belalang kembara jantan } \\
\hline 2 pasang & $2,00 \pm 0,00 \mathrm{a}$ & $3,45 \pm 0,01 \mathrm{e}$ & $5,00 \pm 0,00 \mathrm{e}$ \\
\hline 5 pasang & $1,97 \pm 0,02 b$ & $3,53 \pm 0,00 \mathrm{~d}$ & $5,41 \pm 0,01 \mathrm{~d}$ \\
\hline 10 pasang & $1,97 \pm 0,00 \mathrm{~b}$ & $3,69 \pm 0,01 \mathrm{c}$ & $5,69 \pm 0,01 \mathrm{c}$ \\
\hline 20 pasang & $1,91 \pm 0,02 \mathrm{c}$ & $3,93 \pm 0,00 \mathrm{~b}$ & $6,03 \pm 0,01 b$ \\
\hline 30 pasang & $1,81 \pm 0,02 \mathrm{~d}$ & $4,09 \pm 0,00 \mathrm{a}$ & $6,20 \pm 0,00 \mathrm{a}$ \\
\hline Nilai-F & 547,14 & 364,54 & 4670,83 \\
\hline Nilai-P & 0,0001 & 0,0001 & 0,0001 \\
\hline \multicolumn{4}{|c|}{ Belalang kembara betina } \\
\hline 2 pasang & $2,00 \pm 0,003$ a & $3,54 \pm 0,004 \mathrm{~d}$ & $5,03 \pm 0,005$ e \\
\hline 5 pasang & $1,97 \pm 0,002 b$ & $3,55 \pm 0,003 d$ & $5,52 \pm 0,004 d$ \\
\hline 10 pasang & $1,96 \pm 0,001 \mathrm{~b}$ & $3,79 \pm 0,003 \mathrm{c}$ & $5,78 \pm 0,005 \mathrm{c}$ \\
\hline 20 pasang & $1,89 \pm 0,002 \mathrm{c}$ & $3,96 \pm 0,001 b$ & $6,10 \pm 0,004 b$ \\
\hline 30 pasang & $1,74 \pm 0,001 \mathrm{~d}$ & $4,19 \pm 0,002$ a & $6,20 \pm 0,003 a$ \\
\hline Nilai-F & 438,70 & 1120,57 & 1348,74 \\
\hline Nilai-P & 0,0001 & 0,0001 & 0,0001 \\
\hline
\end{tabular}

Keterangan:

Nilai F dan P diperoleh dari analisis sidik ragam. Pembandingan nilai tengah dilakukan dengan uji BNT pada taraf nyata 5\%. Nilai rata-rata yang berada dalam satu kolom yang diberi huruf yang sama tidak berbeda menurut uji BNT pada taraf 5\%.

kemudian segera diikuti oleh perubahan fisik dan perilaku dari nimfa (belalang muda) dari populasi yang sama. Pada populasi belalang kembara di Madagaskar, warna fisik nimfa berubah dari hijau kecoklatan pada fase soliter menjadi kuning coklat pada fase gregarius. Dalam percobaan ini juga terlihat dengan jelas bahwa secara visual (kualitatif) belalang kembara yang dipelihara pada koloni yang lebih padat cenderung mempunyai warna integumen lebih gelap. Kondisi seperti ini, menurut Loher (1990) terjadi karena perubahan kepadatan populasi menyebabkan perubahan yang reversibel dalam pigmentasi, morfometri, fisiologi, dan perilaku belalang kembara.

Selain berpengaruh terhadap daya makan dan morfometrik belalang kembara, kepadatan koloni juga berpengaruh terhadap mortalitas koloni. Persentase 
Tabel 4. Rasio E/F (sayap - femur), F/C (femur - lebar frons), dan fase belalang kembara jantan setelah berada dalam kepadatan berbeda-beda.

\begin{tabular}{cccc}
\hline $\begin{array}{c}\text { Perlakuan Jumlah belalang/ } \\
\text { kurungan) }\end{array}$ & Rasio E/F & Rasio F/C & $\begin{array}{c}\text { Fase Belalang } \\
\text { Kembara** }\end{array}$ \\
\hline Belalang kembara jantan & & & \\
\hline 2 pasang & $1,73 \pm 0,005$ & $3,99 \pm 0,003$ & Soliter \\
5 pasang & $1,79 \pm 0,001$ & $3,65 \pm 0,002$ & Soliter/Transiens* \\
10 pasang & $1,88 \pm 0,002$ & $3,46 \pm 0,002$ & Transiens \\
20 pasang & $2,06 \pm 0,002$ & $3,17 \pm 0,004$ & Transiens \\
30 pasang & $2,26 \pm 0,004$ & $2,92 \pm 0,002$ & Gregarius \\
\hline & & & \\
\hline Belalang kembara betina & & & Soliter \\
\hline 2 pasang & $1,77 \pm 0,00$ & $3,97 \pm 0,01$ & Transiens \\
10 pasang & $1,80 \pm 0,00$ & $3,57 \pm 0,01$ & Transiens \\
20 pasang & $1,93 \pm 0,00$ & $3,39 \pm 0,01$ & Gregarius \\
\hline 30 pasang & $2,09 \pm 0,00$ & $3,10 \pm 0,01$ & \\
\hline
\end{tabular}

Keterangan:

*) Belalang kembara jantan pada hasil rasio E/F berada pada soliter ; hasil rasio F/C berada pada fase transien.

**) Berdasarkan kriteria Luong-Skovmand (1999).

mortalitas cenderung semakin tinggi pada koloni yang lebih padat, terutama pada nimfa instar 3 (pengamatan 1 - 15 hari) meskipun pada pengamatan hari ke 16-30 dan 31-45 persentase mortalitas tidak selalu konsisten sementara pada tingkat koloni yang tinggi tidak selalu terjadi mortalitas yang lebih tinggi (Tabel 5).

Kematian belalang kembara di dalam kurungan pada percobaan ini kemungkinan besar disebabkan oleh faktor kompetisi antarindividu (kompetisi intraspesifik) terutama di dalam memperebutkan ruang (space competition) dan makanan meskipun di dalam percobaan ini jumlah pakan disediakan mencukupi. Mortalitas yang tinggi pada koloni yang lebih padat diduga juga berkaitan dengan meningkatnya pergerakan dan aktivitas belalang akibat bekerjanya feromon gregarisasi. Dalam kondisi yang lebih padat ini diduga belalang menjadi lebih agresif dan suhu koloni meningkat dan diikuti dengan kadar kontaminasi akibat kotoran yang meningkat. Faktor-faktor tersebut secara akumulatif dapat menyebabkan meningkatnya mortalitas koloni belalang kembara pada kondisi terjadinya kompetisi antarindividual (Joern \& Gaines, 1990). 
Tabel 5. Persentase kematian belalang kembara pada beberapa tingkat kepadatan populasi.

\begin{tabular}{lccc}
\hline Perlakuan (Jumlah & \multicolumn{3}{c}{ Rerarata Kematian Belalang Kembara (\%) } \\
\cline { 2 - 4 } Belalang/Kurungan) & Hari 1-15 & Hari 16-30 & Hari 31-45 \\
\hline 2 pasang & $12,50 \pm 5,8 \mathrm{~b}$ & $12,50 \pm 6,25 \mathrm{~d}$ & $0,00 \pm 0,00 \mathrm{c}$ \\
5 pasang & $13,75 \pm 1,25 \mathrm{~b}$ & $10,00 \pm 2,04 \mathrm{a}$ & $20,00 \pm 2,04 \mathrm{a}$ \\
10 pasang & $18,75 \pm 2,14 \mathrm{~b}$ & $21,25 \pm 3,29 \mathrm{a}$ & $11,25 \pm 2,14 \mathrm{ab}$ \\
20 pasang & $46,88 \pm 0,79 \mathrm{a}$ & $21,88 \pm 1,79 \mathrm{a}$ & $2,50 \pm 0,51 \mathrm{bc}$ \\
30 pasang & $51,25 \pm 2,21 \mathrm{a}$ & $12,92 \pm 1,09 \mathrm{a}$ & $10,00 \pm 1,63 \mathrm{~b}$ \\
\hline Nilai-F & 8,42 & 0,59 & 7,25 \\
\hline Nilai-P & 0,0018 & 0,6746 & 0,0033 \\
\hline
\end{tabular}

Keterangan: Nilai $\mathrm{F}$ dan $\mathrm{P}$ diperoleh dari analisis ragam dan Uji BNT pada taraf nyata 5\%. Nilai rata-rata sekolom yang diikuti huruf yang sama tidak berbeda nyata menurut uji BNT pada taraf nyata 5\%.

\section{SIMPULAN}

Hasil percobaan menunjukkan bahwa belalang kembara yang dipelihara di rumah kaca dalam kepadatan populasi tinggi secara umum cenderung lebih rakus daripada mereka yang dipelihara dalam kepadatan populasi rendah. Pada kepadatan 2-5 pasang per kurungan, daya makan belalang kembara adalah 0,56 - 2,06 g/ekor/hari. Pada kepadatan 10 pasang, kisaran volume makan belalang kembara adalah 2,33 - 2,73 g/ekor/hari. Sementara itu, pada koloni 20 - 30 pasang per kurungan, adalah 3,39 - 4,72 g/ekor/hari. Belalang kembara tetap berada dalam fase soliter pada kepadatan koloni 2 - 5 pasang per kurungan. Selanjutnya belalang kembara berubah dari fase soliter ke fase transien pada kepadatan koloni 10 - 20 pasang per kurungan. Perubahan ke fase gregarius terjadi ketika koloni belalang kembara berada pada kepadatan 30 pasang per kurungan. Persentase mortalitas cenderung semakin tinggi pada koloni yang lebih padat, terutama pada nimfa instar 3 .

\section{SANWACANA}

Percobaan ini merupakan bagian dari penelitian yang dibiayai RUT VIII (2001-2002). Penulis mengucapkan terima kasih kepada Pimpinan Proyek RUT atas dukungan dananya. Ucapan terima kasih juga disampaikan kepada Sdr. Chairil, mahasiswa Jurusan Proteksi Tanaman, Fakultas
Pertanian Universitas Lampung yang membantu pelaksanaan dan pengamatan dalam percobaan ini dalam rangka tugas akhir skripsinya serta kepada Ir. Agus M. Hariri, M.S. yang telah memberikan banyak masukan dalam pembahasan/seminar dari percobaan ini. Para penulis juga berterimakasih kepada Ir. I Gede Swibawa, M.S. yang telah terlibat di dalam sebagian penelitian ini.

\section{DAFTAR PUSTAKA}

Dale, J.F. \& S.S. Tobe. 1990. The endocrine basis of locust phase polymorphism. In Chapman \& Joern (eds.), Biology of Grashoppers. John Wiley \& Sons. New York.

Ellis, P.E. 1953. Social agregation and gregarious behaviour in hoppers of Locusta migratoria migratoriodes R. \& F.). Behaviour 5, 225-260.

Gillett, S. D. 1975. The action of gregarisastion pheromone on five non-behavioral characters of phase polymorphism of the desert locust Schistocera gregaria (Forskal). Acrida 4, $137-149$.

Gillett, S.D. 1983. Primer pheromones and plymorphism in the desert locust. Animal Behavior, 31: 221-230. 
Joern, A. \& S. B. Gaines. 1990. Population and dynamics and regulation in grasshoppers. In Chapman \& Joern (eds.), Biology of Grashoppers. John Wiley \& Sons. New York.

Kalshoven, L.G.E. 1981. Pests of crops of Indonesia. Revised and translated by P.A. Van Der Laan). PT Ichtiar Baru-Van Hoeve. Jakarta.

Karlson, P. \& A. Butenandt. 1959. Pheromones (ectohormones) in insects. Annu. Rev. Entomol. 4: 39-58.

Kompas. 1998. Belalang Serang Lima Propinsi. Harian Kompas, 4 Mei 1999.

Lecoq, M. 1999. Outbreaks of the oriental migratory locust in Indonesia. Unpublished paper presented in "Seminar for technology transfer of locust survey and control". Lampung, 12-16 July 1999.
Loher, W. 1990. Pheromones and phase transformation in locusts. In Chapman \& Joern eds.), Biology of Grashoppers. John Wiley \& Sons. New York.

Luong-Skovmand. 1999. Biology of the oriental migratory locust. Unpublished paper presented in "Seminar for technology transfer of locust survey and control". Lampung, 12-16 July 1999.

Nolte, D. J. 1976. Locustol and its analogues. J. Insect Physiol., 22: 833-838.

Nolte, D. J. 1977. The action of locustol. J. Insect Physiol., 23: 899-903.

SAS Institute Inc. 2000. SAS/STAT User's Guide. Release 8.01 Edition. Cary, NC. 